P ISSN : 2503 - 1708

E ISSN : 2722 - 7340

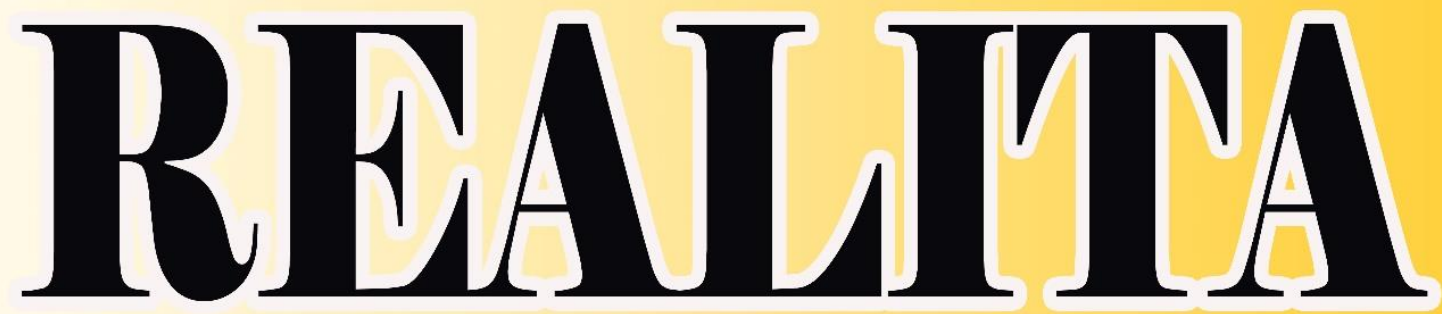

Jurnal Bimbingan dan Konseling

\begin{tabular}{|c|c|c|c|c|c|}
\hline JURNAL & VOLUME & NOMOR & EDISI & HALAMAN & P ISSN : 2503 - 1708 \\
REALITA & 6 & 2 & Oktober 2021 & $1326-1430$ & E ISSN : 2722 - 7340 \\
\hline
\end{tabular}

Diterbitkan oleh:

PROGRAM STUDI BIMBINGAN DAN KONSELING FAKULTAS ILMU PENDIDIKAN DAN PSIKOLOGI UNIVERSITAS PENDIDIKAN MANDALIKA 


\section{REALITA \\ BIMBINGAN DAN KONSELING \\ Jurnal Penelitian dan Pengembangan Pendidikan}

\section{DEWAN REDAKASI \\ Pelindung : Rektor Universitas Pendidikan Mandalika \\ : Dekan FIPP Universitas Pendidikan Mandalika \\ Penanggung \\ Jawab \\ : Kaprodi BK FIPP Universitas Pendidikan Mandalika \\ Editor}

Hariadi Ahmad, M.Pd

Universitas Pendidikan Mandalika

Associate Editor

Mustakim, M.Pd

Universitas Pendidikan Mandalika

Mujiburrahman, M.Pd

Universitas Pendidikan Mandalika

Ahmad Muzanni, M.Pd

Universitas Pendidikan Mandalika

M. Chaerul Anam, M.Pd

Universitas Pendidikan Mandalika

\section{Editorial Board}

Prof. Drs. Kusno, DEA., Ph.D

Universitas Negeri Jember Jawa Timur

Drs. Wayan Tamba, M.Pd

Farida Herna Astuti, M.Pd

Ichwanul Mustakim, M.Pd

Reza Zulaifi, M.Pd

Jessica Festi Maharani, M.Pd

Universitas Pendidikan Mandalika

Universitas Pendidikan Mandalika

Universitas Pendidikan Mandalika

Universitas Pendidikan Mandalika

Universitas Pendidikan Mandalika

\section{Reviwer}

Dr. I Made Sonny Gunawan, S.Pd., M.Pd

Universitas Pendidikan Mandalika

Dr. A. Hari Witono, M.Pd

Universitas Mataram NTB

Prof. Dr. Wayan Maba

Universitas Mahasaraswati Bali

Dr. Gunawan, M.Pd

Universitas Mataram NTB

Dr. Haromain, S.Pd., M.Pd.

Universitas Pendidikan Mandalika

Dr. Hadi Gunawan Sakti, M.Pd

Wiryo Nuryono, M.Pd

Hasrul, S.PdI., M.Pd

Dita Kurnia Sari, M.Pd

Dr. Roro Umy Badriyah. M.Pd., Kons

Universitas Pendidikan Mandalika

Universitas Negeri Surabaya Jawa Timur

STKIP Kie Raha Ternate Maluku Utara

UIN Sunan Ampel Surabaya Jawa Timur

Universitas PGRI Maha Dewa Bali

Ari Khusumadewi, M.Pd

Universitas Negeri Surabaya Jawa Timur 
M. Najamuddin, M.Pd

M. Samsul Hadi, M.Pd

Lalu Jaswandi, M.Pd

Eneng Garnika, M.Pd

Aluh Hartati, M.Pd

Drs. I Made Gunawan, M.Pd

Nuraeni, S.Pd., M.Si

Baiq Sarlita Kartiani, M.Pd

M. Zainuddin, M.Pd

Ahmad Zainul Irfan, M.Pd

Dra. Ni Ketut Alit Suarti, M.Pd

Asep Sahrudin, S.Pd., M.Pd

Suciati Rahayu Widyastuti, S.Pd., M.Pd

Rahmawati M, S.Pd., M.Pd

Ginanjar Nugraheningsih, S.Pd. Jas., M.Or

Dewi Ariani, S.Pd., M.Pd

St. Muriati, S.Pd., M.Pd

Uli Agustina Gultom, S.Pd., M.Pd

Indra Zultiar, S.Pd., M.Pd.
Universitas Pendidikan Mandalika

Universitas Pendidikan Mandalika

Universitas Pendidikan Mandalika

Universitas Pendidikan Mandalika

Universitas Pendidikan Mandalika

Universitas Pendidikan Mandalika

Universitas Pendidikan Mandalika

Universitas Pendidikan Mandalika

Universitas Pendidikan Mandalika

Universitas Pendidikan Mandalika

Universitas Pendidikan Mandalika

Univ. Mathla'ul Anwar Banten

Univ. Nahdlatul Ulama Cirebon

Universitas Muhammadiyah Kendari Sulawesi Tenggara

Universitas Mercu Buana Yogyakarta

Universitas Mahaputra Muhammad Yamin Solok Sumatera Barat

Universitas Bosowa Makassar Sulawesi Selatan

Universitas Borneo Tarakan Kalimantan Utara

Universitas Muhammadiyah Sukabumi Jawa Barat

\section{Alamat Redaksi:}

Redaksi Jurnal Realita Bimbingan dan Konseling (JRbk)

Program Studi Bimbingan dan Konseling

Fakultas Ilmu Pendidikan dan Psikologi Universitas Pendidikan Mandalika

Gedung Dwitiya, Lt. 3 Jalan Pemuda No. 59 A Mataram Telp. (0370) 638991

Email : realita@undikma.ac.id

Web : e-journal.undikma.ac.id

Jurnal Realita Bimbingan dan Konseling menerima naskah tulisan penulis yang original (belum pernah diterbitkan sebelumnya) dalam bentuk soft file, office word document (Email) atau Submission lansung di akun yang diterbitkan setiap bulan April dan Oktober setiap tahun.

Diterbitkan Oleh: Program Studi Bimbingan dan Konseling Fakultas Ilmu Pendidikan dan Psikologi Universitas Pendidikan Mandalika. 


\section{DAFTAR ISI}

Halaman

\section{Nuraeni dan Mastari}

Pengaruh Konseling Kelompok Terhadap Self Esteem Siswa Kelas XI di SMK Negeri 2 Kuripan

\section{Aprilia Yolanda, Ni Ketut Alit Suarti dan Ahmad Muzanni}

Pengaruh Body Shaming Terhadap Kepercayaan Diri Siswa SMA Negeri

1 Batulayar

$1342-1353$

\section{Hariadi Ahmad}

Hubungan Kestabilan Emosi dengan Kontrol Diri Siswa Sekolah Menegah Pertama

\section{Aluh Hartati}

Pengaruh Teknik Modeling Untuk Meningkatkan Empati Siswa

\section{Mustakim}

Pengaruh Teknik Cerita Terhadap Sikap Kemandirian Anak Pada Usia 5-6 Tahun

\section{Farida Herna Astuti dan Ichwanul Mustakim}

Keefektifan Bimbingan Kelompok dengan Teknik Role Playing untuk Meningkatkan Motivasi Belajar

\section{Mujiburrahman dan Soba Al-Qadri}

Hubungan Antara Kemampuan Kontrol Diri Dengan Penyusaian Diri Pada Siswa Kelas XI SMA Negeri 1 Taliwang

\section{Wiwiek Zainar Sri Utami}

Pengaruh Konseling Individu Terhadap Potensi Diri Anak Tunarungu di Sekolah Inklusi

\section{Baiq Nur'aini Cahya Khairani dan Ni Made Sulastri}

Pengaruh Layanan Konseling Humanistik Terhadap Perilaku Agresif pada Siswa Kelas XI IPS-4 di SMA Negeri 7 Mataram

\section{Najamudin}

Pengaruh Teknik Biblioterapi Terhadap Sikap Kemandirian Belajar Pada Siswa VIII SMP Negeri 5 Lembar

\section{Khaerul Huda}

Meningkatkan Pengetahuan dan Pemahaman Perilaku Hidup Bersih dan Sehat dimasa Covid 19 Melalui Metode Demontrasi pada Kelompok B di TK Negeri 01 Wanasaba 


\title{
KEEFEKTIFAN BIMBINGAN KELOMPOK DENGAN TEKNIK ROLE PLAYING UNTUK MENINGKATKAN MOTIVASI BELAJAR
}

\author{
Farida Herna Astuti dan Ichwanul Mustakim \\ Dosen Program Studi Bimbingan dan Konseling, Fakultas Ilmu Pendidikan dan \\ Psikologi Universitas Pendidikan Mandalika, Mataram, NTB, Indonesia \\ Email: faridaherna675@gmail.com, ichwanu104mu@gmail.com,
}

\begin{abstract}
Abstrak. Motivasi memegang peranan yang penting dalam proses belajar. Apabila guru dan orang tua dapat memberikan motivasi yang baik pada siswa atau anaknya, maka dalam diri siswa atau anak akan timbul dorongan dan hasrat untuk belajar lebih baik. tujuan yang ingin dicapai dalam penelitian ini adalah untuk mengetahui tingkat keefektifan bimbingan kelompok dengan teknik role playing. Metode menggunakan desain penelitian one group pree test dan post test design. hasil perhitungan dengan menggunakan rumus diperoleh nilai $t$ hitung untuk kelompok ekperimen sebesar 27.399, sedangkan nilai $t$-tabel dengan $\mathrm{db}=8-1=$ 7 dan taraf signifikansi 5\% adalah sebesar 2.365, yang berarti nilai t-hitung lebih besar dari t-tabel $(27.399>2.365)$. Layanan bimbingan kelompok dengan teknik role playing efektif untuk meningkatkan motivasi belajar siswa di dalam penerapannya.
\end{abstract}

Kata Kunci: Bimbingan Kelompok, Teknik Role Playing, Motivasi Belajar

\section{PENDAHULUAN}

Motivasi adalah perubahan tenaga di dalam diri seseorang yang ditandai dengan dorongan yang berasal dari diri seseorang untuk mencapai tujuan. Dorongan dan reaksi-reaksi usaha yang disebabkan karena adanya kebutuhan untuk berprestasi dalam hidup. Hal tersebut menjadikan individu memiliki usaha, keinginan dan dorong untuk mencapai hasil belajar yang tinggi. Bahwa Hasil belajar merupakan cerminan kemampuan penguasaan seseorang atas mata pelajaran yang diajarkan. Hasil belajar yang tinggi merupakan lambang keberhasilan seseorang siswa dalam studinya. Peserta didik yang memiliki hasil belajar yang tinggi menunjukkan bahwa yang bersangkutan memiliki tingkat kemampuan penguasaan yang tinggi pula terhadap mata pelajaran yang diprogramkan, demikian pula sebaliknya. Dalam pembelajaran faktor motivasi mempunyai pengaruh penting. Motivasi merupakan salah satu faktor yang sangat menentukan hasil belajar peserta didik, dalam hal ini yang menjadikan perilaku untuk bekerja atau belajar dengan penuh inisiatif, kreatif dan terarah. Siswa yang memiliki motivasi belajar tinggi, akan selalu berusaha untuk lebih baik dan ingin selalu dipandang sebagai siswa yang berhasil dalam lingkungannya.

Banyak teori tentang motivasi manusia telah dikembangkan oleh ahli psikologi yang bekerja dalam satu dari tiga kerangka teori besar, yaitu: behaviorisme, psikologi kognitif, dan humanisme. Para ahli yang menganut paham bahavior mengatakan bahwa motivasi berawal dari situasi, kondisi dan objek yang menyenangkan. Jika hal ini memberi kepuasan yang berkelanjutan maka akan menimbulkan tingkah laku yang siap untuk melakukan sesuatu. Kaum paham kognitif mengatakan bahwa yang mempengaruhi perilaku individu adalah proses pemikiran, karena penganut paham kognitif memfokuskan 
pada bagaimana individu memproses informasi dan memberikan penafsiran untuk situasi khusus. Penganut paham humanis mengatakan bahwa manusia bertindak dalam situasi lingkungan dan membuat pilihan mengenai apa yang dilakukan, tetapi mereka lebih menaruh perhatian pada jalan umum perkembangan seseorang, aktivitas dari potensi dan menghilangkan gangguangangguan pada pertumbuhan seseorang.

Dari Koeswara mengatakan bahwa dalam disiplin ilmu psikologi, motivasi merupakan konsep yang digunakan untuk menerangkan kekuatankekuatan yang ada dan bekerja pada diri organisme atau individu yang menjadi penggerak dan pengarah tingkah laku individu tersebut. Para teoritikus motivasi dalam menyusun konsepsi teori mengenai motivasi bisa dikategorikan dalam tiga pendekatan yang utama, yakni: (1) pendekatan biologis, (2) pendekatan behavioristik, dan (3) pendekatan kognitif. Teeven dan Smith dalam Martaniah menyatakan bahwa motivasi adalah konstruk dan pengaktifan perilaku, sedangkan komponen yang lebih spesifik dari motivasi yang berhubungan dengan tipe-perilaku tertentu disebut motif.11 Motif merupakan faktor penggerak yang menyebabkan timbulnya perilaku tertentu, sedangkan motivasi struktur dari berbagai motif yang timbul pada diri seseorang.

Bimbingan kelompok identik dengan upaya pencagahan suatu masalah, sehingga tentunya akan ada materi yang berusaha disampaikan oleh pemimpin kelompok (konselor) untuk dapat dipahami oleh angota kelompok (klien). Winkel dan Hastuti (2010) mengatakan bahwa "bimbingan adalah proses membantu orang perorang dalam memahami dirinya dan lingkungan", selanjutnya dinyatakan bahwa "kelompok berarti kumpulan dua orang atau lebih". Bimbingan kelompok adalah layanan bimbingan yang diberikan kepada lebih dari satu orang pada waktu yang bersamaan (Winkel dan Hastuti, 2015). Menurut Gibson dan Mitchell (2014), bahwa bimbingan kelompok adalah bimbingan yang mengacu kepada aktivitas-aktivitas kelompok yang berfokus pada penyediaan informasi atau pengalaman lewat aktivitas kelompok yang terencana dan terorganisasi.

Bimbingan kelompok merupakan suatu upaya pemberian bantuan kepada individu melalui kelompok dengan menggunakan dinamika kelompok untuk mendapatkan informasi yang berguna agar mampu menyusun rencana dan keputusan yang tepat serta dapat memahami dirinya sendiri, orang lain, dan lingkungannya dalam menunjang terbentuknya perilaku efektif serta adanya perubahan sikap dalam hidupnya dan mengembangkan dirinya secara optimal. Bermain sering dikaitkan dengan kegiatan anak-anak yang dilakukan secara spontan dan dalam suasana riang gembira. Dengan bermain berkelompok anak akan mempunyai penilaian terhadap dirinya tentang kelebihan yang dimilikinya sehingga dapat membantu pembentukan konsep diri yang positif, pengelolaan emosi yang baik, memiliki rasa empati yang tinggi, memiliki kendali diri yang bagus, dan memiliki rasa tanggung jawab yang tinggi.

Blatner (2009) mengemukakan bahwa "bermain peran (sosiodrama) adalah metode untuk mengembangkan isu yang terjadi di dalam masyarakat sosial yang kompleks. Selanjutnya juga dikemukakan bahwa bermain peran dapat membantu menjadi lebih tertarik dan terlibat, bukan hanya belajar tentang materi tetapi juga belajar untuk mengintegrasikan pengetahuan ke dalam tindakan, bagaimana menghadapi masalah, mengembangkan alternatif- 
alternatif dan mencari solusi baru yang kreatif'. Artinya bahwa bermain peran merupakan kegiatan yang bernuansa sosial yang memungkinkan pesertanya untuk melakukan identifikasi berbagai ketrampilan sosial lewat permainan imajiner yang dilakukan dalam kelompok. Role play terjadi disaat ini, bukan dimasa mendatang, teknik ini lazim dimulai dengan adegan-adegan yang lebih mudah untuk diperankan dan secara progresif ditingkatkan ke adeganadegan yang lebih kompleks (Erford, 2016). Role playing merupakan cara terbaik untuk mengembangkan ketrampilan berinisiatif, berkomunikasi, memecahkan masalah, dan berlatih kerja sama dalam kelompok. Melalui bermain peran akan membantu siswa untuk lebih siap menghadapi tantangan jaman.

\section{KAJIAN PUSTAKA}

Secara teori banyak ahli menyumbangkan definisi terkait bimbingan kelompok. Bimbingan kelompok identik dengan upaya pencagahan suatu masalah, sehingga tentunya akan ada materi yang berusaha disampaikan oleh pemimpin kelompok (konselor) untuk dapat dipahami oleh angota kelompok (klien). Winkel dan Hastuti (2010) mengatakan bahwa "bimbingan adalah proses membantu orang perorang dalam memahami dirinya dan lingkungan", selanjutnya dinyatakan bahwa "kelompok berarti kumpulan dua orang atau lebih". Bimbingan kelompok adalah layanan bimbingan yang diberikan kepada lebih dari satu orang pada waktu yang bersamaan (Winkel dan Hastuti, 2015). Menurut Gibson dan Mitchell (2014), bahwa bimbingan kelompok adalah bimbingan yang mengacu kepada aktivitas-aktivitas kelompok yang berfokus pada penyediaan informasi atau pengalaman lewat aktivitas kelompok yang terencana dan terorganisasi. Contoh aktivitas bimbingan kelompok adalah kelompok orientasi, kelompok penelusuran karier, dan sebagainya. Wibowo (2013) mengemukakan bahwa bimbingan kelompok merupakan layanan bimbingan dan konseling yang diberikan kepada individu untuk membahas masalah atau topik umum secara luas dan mendalam yang bermanfaat bagi anggota kelompok.

Role Playing sering dikaitkan dengan kegiatan anak-anak yang dilakukan secara spontan dan dalam suasana riang gembira. Dengan bermain berkelompok anak akan mempunyai penilaian terhadap dirinya tentang kelebihan yang dimilikinya sehingga dapat membantu pembentukan konsep diri yang positif, pengelolaan emosi yang baik, memiliki rasa empati yang tinggi, memiliki kendali diri yang bagus, dan memiliki rasa tanggung jawab yang tinggi. Melihat manfaat besar bermain untuk kehidupan anak-anak, dapat dilakukan inovasi menggunakan bermain sebagai model pembelajaran.Karena bermain dapat membantu siswa memahami materi pelajaran lebih mendalam dengan melakukan permainan tentang materi pelajaran yang disajikan.Inovasi pembelajaran yang sudah dilakukan dikenal dengan model pembelajaran bermain peran atau role playing.

Motivasi adalah usaha yang didasari untuk mengerahkan dan menjaga tingkah seseorang agar ia terdorong untuk bertindak melakukan sesuatu sehingga mencapai hasil atau tujuan tertentu. Motivasi belajar adalah suatu perubahan tenaga di dalam diri seseorang (pribadi) yang ditandai dengan timbulnya perasaan dan reaksi untuk mencapai tujuan (Frederick J.Mc. Donald dalam H Nashar, 2011).Tetapi menurut Clayton Aldelfer dalam H.Nashar (2014) motivasi belajar adalah kecenderungan siswa dalam melakuka kegiatan belajar yang didorong oleh hasrat untuk mencapai 
prestasi hasil belajar sebaik mungkin. Motivasi belajar juga merupakan kebutuhan untuk mengembangkan kemampuan diri secara optimum, sehingga mampu berbuat yang lebih baik, berprestasi dan kreatif (Abraham Maslow alam H.Nashar, 2004) motivasi belajar adalah suatu dorongan internal dan eksternal yang menyebabkan seseorang atau individu untuk bertindak atau mencapai tujuan, sehingga perubahan tingkah laku pada diri siswa diharapkan terjadi.

Jadi motivasi belajar adalah kondisi psikologis yang mendorong siswa untuk belajar secara sungguhsungguh, yang pada gilirannya akan terbentuk cara belajar siswa yang sistematis, penuh konsentrasi dan dapat menyeleksi kegiatan-kegiatannya. Agar siswa dapat mencapai hasil belajar yang optimal, maka diperlukan adanya motivasi.Perlu ditekankan bahwa motivasi bertalian dengan suatu tujuan. Sehubungan dengan hal tersebut, ada tiga fungsi motivasi: Mendorong manusia untuk berbuat. Jadi, sebagai penggerak atau motor yang melepaskan energi. Motivasi dalam hal ini merupakan motor penggerak dari setiap kegiatan yang akan dikerjakan. Menentukan arah perbuatan, yakni kea rah tujuan yang hendak dicapai. Dengan demikian motivasi dapat memberikan arah dan kegiatan yang harus dikerjakan sesuai dengan rumusan tujuannya. Menyeleksi perbuatan, yakni menentukan perbuatan. Apa yang harus dikerjakan yang serasi guna mencapai tujuan, dengan menyisihkan perbuatanperbuatan yang tidak bermanfaat bagi tujuan tersebut. Seorang siswa yang akan menghadapi ujian dengan harapan dapat lulus, tentu akan melakukan kegiatan belajar dan tidak akan menghabiskan waktunya untuk bermain kartu atau membaca komik, sebab tidak serasi dengan tujuan.

\section{METODE PENELITIAN}

Pada dasarnya pendekatan penelitian terdiri dari: dua variabel yaitu variabel bebas adalah Bimbingan Kelompok dengan teknik role playing dan variabel terikat adalah motivasi belajar. Variabel bebas dapat memberikan dampak terhadap variabel terikat dengan menggunakan desain penelitian one group pree test dan post test design. "populasi adalah keseluruhan subyek penelitian" (Suharsimi, 2010). Populasi dalam penelitian ini adalah siswa kelas $\mathrm{X}$ SMK Negeri dengan jumlah 30 siswa. Teknik sampling yang digunakan dalam penelitian ini adalah teknik Purposive random sampling yaitu teknik penentuan sampel dengan mengambil sampel atas tujuan tertentu, dengan cara menentukan sejumlah siswa yang memiliki motivasi belajar rendah untuk menjadi sampel penelitian. Dalam penelitian ini menggunakan angket sebagai metode pokok didalam penelitian ini yaitu teknik pengumpulan data yang dilakukan dengan cara memberi pertanyaan secara tertulis kepada responden.

Analisis data yang digunakan untuk menguji hiphotesis dalam penelitian ini adalah analisis statistik, maka rumus yang dipakai dalam analisis data ini adalah rumus $t$-test untuk menganalisis data.Adapun rumus $t$-test.

\section{HASIL DAN PEMBAHASAN}

Dari data hasil pretest dan postest yang telah diperoleh kemudian data tersebut disusun kembali untuk mengetahui perbedaan skor pretest dan posttest. Berikut merupakan hasil pretest dan postestdari kelompok eksperimen dalam penelitian ini:

Tabel. Hasil Data Pretest Dan Posttest Kelompok Eksperimen

\begin{tabular}{|c|c|c|c|c|}
\hline $\begin{array}{c}\text { Nama } \\
\text { siswa } \\
\text { (Inisial) }\end{array}$ & $\begin{array}{c}\text { Skor } \\
\text { pretest }\end{array}$ & kategori & $\begin{array}{c}\text { Skor } \\
\text { posttest }\end{array}$ & Kategori \\
\hline A & 58 & Rendah & 78 & Sedang \\
B & 58 & Rendah & 77 & Sedang \\
C & 56 & Rendah & 75 & Sedang \\
D & 60 & Rendah & 77 & Sedang \\
\hline
\end{tabular}




\begin{tabular}{|l|l|l|l|l|}
\hline E & 60 & Rendah & 78 & Sedang \\
F & 58 & Rendah & 79 & Sedang \\
G & 57 & Rendah & 77 & Sedang \\
H & 60 & Rendah & 75 & Sedang \\
\hline
\end{tabular}

Analisis data dalam penelitian ini dilakukan menggunakan uji statistik nonparametrik yakni uji t atau uji t-tes. Tujuan dilakukannya analisis data dengan menggunakan statistik adalah untuk menjawab hipotesis yang diajukan. Adanya perbedaan sebelum dan sesudah diberikan intervensi menunjukkan keefektifan teknik intervensi yang digunakan sehingga hipotesis penelitian dapat terjawab. Selanjutnya hasil kuesioner motivasi belajar tersebut akan di olah terlebih dahulu dengan menyususn tabel deviasi.

Tabel. Standar Deviasi Pre-Test dan Post-Test Kelompok

Eksperimen

\begin{tabular}{|c|c|c|c|c|c|}
\hline No & Inisial & $\begin{array}{c}\text { Skor } \\
\text { pretes } \\
\text { O1 }\end{array}$ & $\begin{array}{c}\text { Skor } \\
\text { post- } \\
\text { tes O2 }\end{array}$ & $\begin{array}{c}\text { D } \\
\left(\boldsymbol{O}_{\mathbf{2}}-\boldsymbol{O}_{\mathbf{1}}\right)\end{array}$ & $\begin{array}{c}\boldsymbol{d}^{\mathbf{2}} \\
\left(\boldsymbol{O}_{\mathbf{2}}\right. \\
\left.-\boldsymbol{O}_{\mathbf{1}}\right)^{\mathbf{2}}\end{array}$ \\
\hline $\mathbf{( 1 )}$ & $(2)$ & $(3)$ & $(4)$ & $(5)$ & $(6)$ \\
\hline $\mathbf{1}$ & $\mathrm{A}$ & 58 & 78 & 20 & 400 \\
\hline $\mathbf{2}$ & $\mathrm{B}$ & 58 & 77 & 19 & 361 \\
\hline $\mathbf{3}$ & $\mathrm{C}$ & 56 & 75 & 19 & 361 \\
\hline $\mathbf{4}$ & $\mathrm{D}$ & 60 & 77 & 17 & 289 \\
\hline $\mathbf{5}$ & $\mathrm{E}$ & 60 & 78 & 18 & 324 \\
\hline $\mathbf{6}$ & $\mathrm{F}$ & 58 & 79 & 21 & 441 \\
\hline $\mathbf{7}$ & $\mathrm{G}$ & 57 & 77 & 20 & 400 \\
\hline $\mathbf{8}$ & $\mathrm{H}$ & 60 & 75 & 15 & 225 \\
\hline & $\mathrm{E}$ & 467 & 616 & 149 & 2801 \\
\hline & $\mathrm{M}$ & 58.375 & 77 & 18.625 & \\
\hline
\end{tabular}

Dari hasil perhitungan diperoleh nilai t-hitung untuk kelompok ekperimen sebesar 27.399, sedangkan nilait-tabel dengan $\mathrm{db}=8-1=7$ dan taraf signifikansi $5 \%$ adalah sebesar 2.365 , yang berarti nilai $t$-hitung lebih besar dari t-tabel $(27.399>2.365)$. Kenyataan ini menunjukkan bahwa nilai t-hitung yang diperoleh adalah signifikan maka dapat dikemukakan hipotesis alternatif (Ha) yang berbunyi: Bimbingan kelompok dengan teknik role playing efektif mempengaruhi motivasi belajar siswa di SMK Negeri 1 Praya Barat diterima dan hipotesis nol (Ho) ditolak.

\section{KESIMPULAN DAN SARAN}

Layanan bimbingan kelompok dengan teknik role playing efektif untuk meningkatkan motivasi belajar siswa di dalam penerapannya. Hal ini dikarenakan oleh teknik role playing merupakan strategi dalam proses belajar yang dapat diterapkan dalam bidang ilmu bimbingan dan konseling dengan menggali potensi individu untuk menemukan nilai-nilai melaui perasaan, ide-ide, agar dapat menetapkan tujuan di dalam membuat pilihan dan keputusan yang sesuai dengan kenyataannya.

\section{DAFTAR PUSTAKA}

Aluh Hartati, Hariadi Ahmad dan Andika Rifzar Mandasingi. 2020. Hubungan antara Pengendalian Diri dengan Prestasi Siswa SMKN 1 Sumbawa Besar. Realita Jurnal Bimbingan dan Konseling Vol. 5 No 2 Edisi Oktober 2020. Hal 1051 - 1066. Prodi Bimbingan dan Konseling Fakultas Ilmu Pendidikan dan Psikologi Universitas Pendidikan Mandalika.

Arikunto, Suharsimi. 2012. Prosedur Penelitian Suatu Pendekatan Praktik. Jakarta: Rieneka Cipta.

Cresswell J. 2015. Riset Pen Didikan Perencaaan, Pelaksanaan, Dan Evaluasi Riset Kualitatif Dan Kuantitatif. Yogyakarta: Pustaka Pelajar

Gibson, Robbert L dan Marianne H. Mitch ell. 2011. Bimbingan dan Konseling. Yogyakarta: Pustaka Pelajar.

Gladding,Samuel, T. 2011. Konseling: Profesi Yang Menyelururh. Jakarta: Indeks

Hariadi Ahmad dan Aluh Hartati. 2016. Panduan Pelatihan Self Advocacy Siswa SMP untuk Konselor Sekolah. LPP Mandala. Mataram 
Hariadi Ahmad dan Aluh Hartati. 2016. Penerapan Teknik Structure Learning Approach dalam Meningkatkan Self Advocacy Mahasiswa Prodi BK IKIP Mataram. Realita Jurnal Bimbingan dan Konseling Vol. 1 No 2 Edisi Oktober 2016. Hal 117 - 127. Prodi Bimbingan dan Konseling Fakultas Ilmu Pendidikan IKIP Mataram

Hariadi Ahmad dan Dini Kurnia. 2017. Pengaruh Teknik Biblio Edukasi Terhadap Rasa Rendah Diri Pada Siswa Kelas XI di SMA Negeri 8 Mataram. Realita Jurnal Bimbingan dan Konseling Vol. 2 No 1 Edisi April 2017. Hal $194-$ 202. Prodi Bimbingan dan Konseling Fakultas Ilmu Pendidikan IKIP Mataram

Hariadi Ahmad, Ahmad Zainul Irfan dan Dedi Ahlufahmi. 2020. Hubungan antara Pola Asuh Orang Tua dengan Penyesuaian Diri Siswa. Realita Jurnal Bimbingan dan Konseling Vol. 5 No 1 Edisi April 2020. Hal 950 - 966. Prodi Bimbingan dan Konseling Fakultas Ilmu Pendidikan dan Psikologi Universitas Pendidikan Mandalika.

Hariadi Ahmad, Aluh Hartati dan Jessica Festy Maharani. 2020. Pengaruh Dukungan Psikologis Awal pada Remaja dalam Pencegahan Covid 19. Realita Jurnal Bimbingan dan Konseling Vol. 5 No 2 Edisi Oktober 2020. Hal 1091 - 1106. Prodi Bimbingan dan Konseling Fakultas Ilmu Pendidikan dan Psikologi Universitas Pendidikan Mandalika.

Hariadi Ahmad, Aluh Hartati, dan Nuraeni. 2018. Penerapan Teknik Structure Learning Approach (SLA) dalam Meningkatkan Kesadaran Empati Diri Siswa
Madrasah Aliyah Al Badriyah. Realita Jurnal Bimbingan dan Konseling Vol. 3 No 2 Edisi Oktober 2018. Hal 600 - 605 Prodi Bimbingan dan Konseling Fakultas Ilmu Pendidikan IKIP Mataram.

Hariadi Ahmad, dan Lalu Andry Adifa Maulana. 2019. Pengaruh Teknik Video Edukasi Terhadap Berfikir Positif Siswa SMPN 16 Mataram. Realita Jurnal Bimbingan dan Konseling Vol. 4 No 1 Edisi April 2019. Hal 727 - 741. Prodi Bimbingan dan Konseling Fakultas Ilmu Pendidikan IKIP Mataram.

Hariadi Ahmad, dan Yolana Oktaviani. 2019. Pengaruh Teknik Self Instruction Terhadap Harga Diri Siswa Kelas Kelas XI di SMK Negeri 1 Lingsar Kabupaten Lombok Barat. Realita Jurnal Bimbingan dan Konseling Vol. 4 No 2 Edisi Oktober 2019. Hal 806 - 815. Prodi Bimbingan dan Konseling Fakultas Ilmu Pendidikan IKIP Mataram.

Hariadi Ahmad, Lidya Wurru dan Jessica Festy Maharani. 2021. Hubungan antara Keharmonisan Keluarga dengan Perilaku Agresif pada Siswa Madrasah Aliyah Raudlatusshibyan NW Belencong. Realita Jurnal Bimbingan dan Konseling Vol. 6 No 1 Edisi April 2021. Hal 1205 - 1212. Prodi Bimbingan dan Konseling Fakultas Ilmu Pendidikan dan Psikologi Universitas Pendidikan Mandalika.

Hariadi Ahmad, Mustakim dan Syafaruddin. 2018. Hubungan antara Penyesuaian Diri dengan Berfikir Positif Siswa Kelas VIII SMP Negeri Seteluk Kabupaten Sumbawa Barat. Realita Jurnal 
Bimbingan dan Konseling Vol. 3 No 1 Edisi April 2018. Hal 482 494. Prodi Bimbingan dan Konseling Fakultas Ilmu Pendidikan IKIP Mataram

Hasrul dan Hariadi Ahmad. 2021. Mereduksi Prasangka Etnik Siswa dengan Teknik Restructuing Cognitive Suatu Krangka Konseptual. Realita Jurnal Bimbingan dan Konseling Vol. 6 No 1 Edisi April 2021. Hal 1213 - 1222. Prodi Bimbingan dan Konseling Fakultas Ilmu Pendidikan dan Psikologi Universitas Pendidikan Mandalika.
Sardiman,A.M.2012. Interaksi dan Motivasi Belajar Mengajar. Jakarta Grafindo Persada

Sugiyono.2012. Memahami Penelitian Kuantitatif, dan $R \& D$. Bandung: Alfabet

Wibowo, M.E. 2005. Konseling Kelompok Perkembangan. Semarang: UNNES Press

Winkel, W.S. Dan Hastuti, S. 2010. Bimbingan dan Konseling di InstitusiPendidikan. Yogyakarta: Media Abadi

Winkel, W.S. Dan Hastuti, S. 2012. Bimbingan dan Konseling di InstitusiPendidikan. Yogyakarta: Media Abadi. 


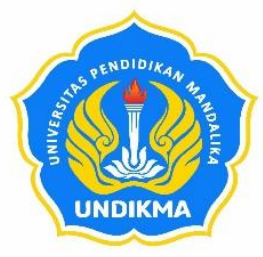

\section{UNIVERSITAS PENDIDIKAN MANDALIKA FAKULTAS ILMU PENDIDIKAN DAN PSIKOLOGI PROGRAM STUDI BIMBINGAN DAN KONSELING Jurnal Realita}

Gedung Dwitiya Lt.3. Jln Pemuda 59A Mataram-NTB 83125 Tlp (0370) 638991 e-mail: realita@undikma.ac.id; web: e-journal.undikma.ac.id

\section{PEDOMAN PENULISAN}

1. Naskah merupakan hasil penelitian, pengembangan atau kajian kepustakaan di bidang pendidikan, pengajaran, pembelajaran, bimbingan dan konseling, dan Psikologi

2. Naskah merupakan tulisan asli penulis dan belum pernah dipublikasikan sebelumnya dalam jurnal ilmiah lain,

3. Naskah dapat ditulis dalam Bahasa Indonesia atau Bahasa Inggris.

4. Penulisan naskah mengikuti ketentuan sebagai berikut:

$\begin{array}{llll}\text { Program } & \text { MS Word } & \text { Margin kiri } & 3.17 \mathrm{~cm} \\ \text { Font } & \text { Times New Roman } & \text { Margin kanan } & 3.17 \mathrm{~cm} \\ \text { Size } & 12 & \text { Margin atas } & 2.54 \mathrm{~cm} \\ \text { Spasi } & 1.0 & \text { Margin bawah } & 2.54 \mathrm{~cm} \\ \text { Ukuran kertas } & \text { A4 } & \text { Maksimum 20 halaman }\end{array}$

5. Naskah ditulis dengan sistematika sebagai berikut: Judul (huruf biasa dan dicetak tebal), nama-nama penulis (tanpa gelar akademis), instansi penulis (program studi, jurusan, universitas), email dan nomor telpon penulis, abstrak, kata kunci, pendahuluan (tanpa sub-judul), metode penelitian (tanpa sub-judul), hasil dan pembahasan, simpulan dan saran (tanpa sub-judul), dan daftar pustaka.

Judul secara ringkas dan jelas menggambarkan isi tulisan dan ditulis dalam huruf kapital. Keterangan tulisan berupa hasil penelitian dari sumber dana tertentu dapat dibuat dalam bentuk catatan kaki. Fotocopy halaman pengesahan laporan penelitian tersebut harus dilampirkan pada draf artikel.

Nama-nama penulis ditulis lengkap tanpa gelar akademis.

Alamat instansi penulis ditulis lengkap berupa nama sekolah atau program studi, nama jurusan dan nama perguruan tinggi. Penulis yang tidak berafiliasi pada sekolah atau perguruan tinggi dapat menyertakan alamat surat elektronik dan nomor telpon.

Abstrak ditulis dalam 2 (dua) bahasa: Bahasa Inggris dan Bahasa Indonesia. Naskah berbahasa Inggris didahului abstrak berbahasa Indonesia. Naskah berbahasa Indonesia didahului abstrak berbahasa Inggris. Panjang abstrak tidak lebih dari 200 kata. Jika diperlukan, tim redaksi dapat menyediakan bantuan penerjemahan abstrak kedalam bahasa Inggris.

Kata kunci (key words) dalam bahasa yang sesuai dengan bahasa yang dipergunakan dalam naskah tulisan dan berisi 3-5 kata yang benar-benar dipergunakan dalam naskah tulisan.

Daftar Pustaka ditulis dengan berpedoman pada Pedoman Penulisan Karya Ilmiah Universitas Pendidikan Mandalika. 


\begin{tabular}{|c|c|c|c|c|c|}
\hline & & & & \\
JURNAL & VOLUME & NOMOR & EDISI & HALAMAN & P ISSN : 2503 - 1708 \\
REALITA & 6 & 2 & Oktober 2021 & $1326-1430$ & E ISSN : 2722 - 7340 \\
& & & & \\
\hline
\end{tabular}

Alamat Qedaksi:

Program Studi Bimbingan dan Konseling Fakultas Ilmu Pendidikan dan Psikologi

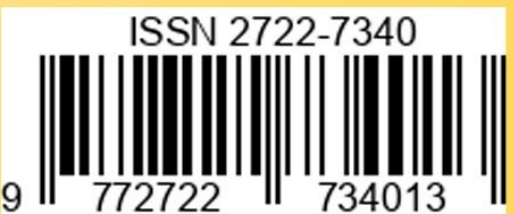

Universitas Pendidikan Mandalika

Gedung Dwitiya, Lt. 3 Jalan Pemuda No. 59A Mataram Telp. (0370) 638991

Email : realita@undikma.ac.id

Web : e-journal.undikma.ac.id

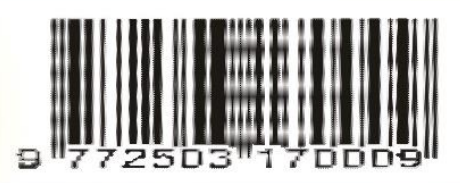

